\title{
TÁTICAS APLICADAS POR SACOLEIROS NA REALIZAÇÃO DO DESCAMINHO NA PONTE DA AMIZADE
}

\author{
Roberto Rigaud Navega Costa ${ }^{1}$ \\ Eric Gustavo Cardin ${ }^{2}$
}

\begin{abstract}
RESUMO: O presente artigo tem como objetivo descrever as táticas dos sacoleiros, compradores de produtos industrializados em Ciudad del Este, no Paraguai, para conseguirem passar suas mercadorias pela Ponte da Amizade, que liga a cidade paraguaia a Foz do Iguaçu, Paraná. Tendo em vista o fato de tais sacoleiros realizarem compras cujos valores mensais ultrapassam o limite de US\$ 300,00 (cota máxima mensal para cada CPF), passar pela fiscalização sem pagar os impostos é fundamental para a manutenção de sua atividade. Para a obtenção dos dados referentes ao texto a seguir realizamos observação participante, nos fazendo passar por sacoleiros e fazendo os mesmos movimentos e táticas para conseguirmos ultrapassar as barreiras alfandegárias implantadas pela Receita Federal brasileira à cabeceira da ponte, em Foz do Iguaçu. Abaixo descreveremos quais são as táticas e seus motivos principais. Esperamos, com a apresentação do presente texto, contribuir para caracterizar os personagens que fazem parte da atividade do descaminho, que atuam na Ponte da Amizade, mostrar suas táticas e lançar luz em uma atividade econômica marginal, que apesar de não ter mais a força que apresentava nas décadas de 1990 até 2010, ainda persiste como meio de obtenção de renda de várias pessoas, tanto de Foz do Iguaçu, quanto de vários municípios do Brasil afora.
\end{abstract}

Palavras-chave: Sacoleiros; Tática; Descaminho; Fronteira.

\section{TÁCTICAS APLICADAS POR LOS SACOLEROS EN EL LOGRO DEL DESCAMINHO SOBRE EL PUENTE DE LA AMISTAD}

RESUMEN: El presente artículo tiene como objetivo describir las tácticas de los carpinteros, compradores de productos industrializados en Ciudad del Este, en Paraguay, para poder pasar sus mercancías por el Puente de la Amistad, que conecta la ciudad paraguaya a Foz do Iguaçu, Paraná. En vista del hecho de que tales bolsas de trabajo realizan compras cuyos valores mensuales sobrepasan el límite de US \$300,00 (cuota máxima mensual para cada $\mathrm{CPF}$ ), pasar por la fiscalización sin pagar los impuestos es fundamental para el mantenimiento de su actividad. Para la obtención de los datos referentes al texto siguiente realizamos la Observación Participante, haciéndonos pasar por bolsas y haciendo los mismos movimientos y tácticas para

\footnotetext{
${ }^{1}$ Bacharel em Filosofia; Mestrando no Programa de Pós-Graduação em Sociedade, Culturas e Fronteiras, Unioeste, Foz do Iguaçu, PR. Contato: ramosnavega@gmail.com

2 Doutor em Sociologia. Pós-doutor em Antropologia, Professor de Ciências Sociais na Universidade Estadual do Oeste do Paraná (UNIOESTE). Pesquisador do Laboratório de Pesquisa Fronteiras, Estado e Relações Sociais (LAFRONT). Contato: eric_cardin@ hotmail.com
}

Programas de Pós-Graduação em Ciências Sociais e Filosofia - UNIOESTE - Rua da Faculdade 645. Toledo - PR. CEP 85.903-000 Email: revistaalamedas@gmail.com 
conseguir superar las barreras aduaneras implantadas por la Receita Federal brasileña a la cabecera del puente, en Foz do Iguaçu. A continuación, describiremos cuáles son las tácticas y sus motivos principales. En el caso de que se produzca un cambio en la calidad de vida de las personas que viven en el país, se debe tener en cuenta que, en las décadas de 1990 hasta 2010, todavía persiste como medio de obtención de renta de varias personas, tanto de Foz do Iguaçu, como de varios municipios de Brasil afuera.

Palabras clave: Sacolero; Tácticas; Malversación de Fondos; Frontera.

\section{INTRODUÇÃO}

Para melhor contextualizarmos o tema em questão acreditamos ser necessário fazer um retorno ao começo do processo de reinvenção da cidade de Foz do Iguaçu, que passa de território de extração de erva mate, de extração de madeira, a um importante entroncamento na exportação de produtos agrícolas do Paraguai. Aproveitando-se desta posição privilegiada o Governo Paraguaio implantou uma "zona de tributação diferenciada" (CARDIN, 2018) na margem paraguaia do Rio Paraná, dando origem a Puerto Stroessner, mais tarde Ciudad del Este, servindo assim, de um polo de comércio de produtos industrializados provenientes, principalmente, da Ásia. É neste desenvolvimento que surge a figura do sacoleiro, o foco de nosso trabalho atual.

Para poder exercer sua atividade econômica subterrânea é preciso que os sacoleiros possam aproveitar-se da diferença de preços relativos que existe entre o Brasil e o Paraguai. Não se trata de cotação do dólar, mas de uma política de impostos diferenciada, que faz com que os produtos importados tenham preços muito abaixo dos praticados nas lojas brasileiras em todo o território nacional. Esta diferença de preços é o que impulsiona caravanas de compradores a se arriscarem, e a arriscar suas poupanças, já que não podem contar com créditos bancários, por serem informais e ilegais. São as táticas que os sacoleiros empregam para obterem êxito em sua atividade que iremos apresentar neste trabalho.

Assim, pretendemos discutir no presente trabalho como o sacoleiro se articula e se organiza para fazer frente à sua principal barreira na obtenção de algum lucro no processo de compra e venda de mercadorias adquiridas acima da cota, estabelecida pela Receita Federal, e se livrar de ter seus produtos sobretaxados, ou pior apreendidos, no processo de fiscalização. Com isto pretendemos mostrar as dificuldades inerentes a 
atividade de sacoleiro e como os sujeitos se empenham para exercerem suas atividades econômicas.

Para a obtenção de dados referentes a confecção deste trabalho optamos por nos misturarmos aos sacoleiros, passando a exercer sua atividade, tentando não chamar a atenção para diferenças de postura, vestimenta, hábitos, não anotar, não gravar, não perguntar nada além das conversas corriqueiras que surgem no próprio contato humano. O método que se demonstrou mais eficaz para obtermos as informações necessárias foi o da observação participante, pois no processo de estarmos com os sacoleiros poderíamos diminuir as interferências oriundas da presença do pesquisador.

Em “A interpretação das Culturas", Clifford Geertz (2008) faz uma ótima avaliação dos métodos que utilizou para estudar a cultura dos moradores da Ilha de Java, na Indonésia. Para tal, abriu um enorme leque de conceitos e de informações a respeito de tais conceitos, formando um ótimo quadro da cultura e da vida do povo estudado. Podemos ver em seu texto toda a força do método etnográfico e da utilização da observação participante na prática. Tanto que para Geertz (2001) os antropólogos se definem mais pelo estilo de pesquisa do que por seu objeto.

Bezerra (2010) nos informa a respeito dos procedimentos etnográficos próprios da Antropologia, mas assimilados às Ciências Sociais, História, Comunicação, Geografia, entre outras áreas. Sendo um procedimento metodológico poderoso na investigação de variáveis comportamentais de grupos sociais, procurando fazer uma descrição mais densa das características próprias de tais grupos.

Ainda com Bezerra (Iden) vemos que o trabalho etnográfico da observação participante se dá em campo, onde podem ocorrer uma série de imprevistos, que em sua soma podem contribuir para uma visão, e uma descrição mais rica do objeto de estudo a que o investigador se propõe em sua pesquisa, evitando assim, uma visão rasa, e uma descrição superficial dos fatos observados.

Malinowski inaugura, com seu trabalho etnográfico nas ilhas Trobriand vivendo isoladamente com os habitantes locais de 1914 a 1918, uma forma de se relacionar com o objeto de pesquisa, onde se evita apenas o pesquisador teórico, mas valoriza-se o pesquisador de campo, que passa, aliando a teoria à prática, a poder compor um cenário mais vivo da realidade percebida, não em curtas visitas à campo, mas em prolongadas vivências em meio ao grupo pesquisado (BEZERRA, 2010, p. 6). 
A cultura pensada como um conjunto de comportamentos, costumes, hábitos, rituais e crenças, de certa forma determina o poder da observação. A presença do pesquisador como observador-participante ficou estabelecida como metodologia legítima a partir de Malinowski que questionou a validade das informações de informantes nativos, por vezes perpassadas de interesses ou interpretações diversas,além do mais, a observação criteriosa por parte do pesquisador se faz a partir de certos métodos e desprendidas de interesses (BEZERRA, 2010, p. 8).

O texto se divide em um breve histórico a respeito de Foz do Iguaçu e sua articulação com Ciudad del Este, onde buscaremos entender sua função como polo de atividade sacoleira. Após, discorremos um pouco a respeito do método de observação participante, que empregamos para obter nossos dados de pesquisa. A seguir apresentamos o conceito de tática e suas diferenças em relação ao conceito de estratégia. Por fim, descreveremos as táticas empregadas pelos sacoleiros para a passagem da ponte e da Receita Federal do Brasil.

\section{A FRONTEIRA FOZ DO IGUAÇU - CIUDAD DEL ESTE}

A cidade de Foz do Iguaçu nasceu da necessidade de que houvesse uma presença permanente de população na fronteira entre Brasil, Argentina e Paraguai. Inicialmente a ocupação se deu através da militarização desta parte do território, com a criação em 1897 de uma colônia militar, com o intuito de trazer aos poucos uma população que ocupasse e mantivesse a segurança desta parte do país.

Segundo Fernando Raphael Ferro de Lima (2011), o governo brasileiro, a partir de Getúlio Vargas, tenta minar a influência da Argentina na região do Prata, ajudando Paraguai e Bolívia a escoar suas produções, e a fazerem comércio utilizando o território brasileiro como alternativa à navegação no Rio da Prata. Tais medidas trouxeram ainda mais tráfego local à fronteira entre Brasil e Paraguai, especialmente na região de Foz do Iguaçu e a cidade de Puerto Stroessner, antigo nome de Ciudad del Este. O crescente interesse geopolítico por parte dos militares na produção de energia trouxe mais uma vez o foco do governo brasileiro à região de Foz do Iguaçu, e trouxe mais uma ligação entre Brasil e Paraguai, o que originou a construção da Usina Hidrelétrica de Itaipu. 
Ciudad del Este reinventou-se como polo de comércio de produtos importados, tendo como principais clientes os brasileiros que compravam mais barato tais produtos para revender no Brasil. Estes compradores foram apelidados de muambeiros e/ou de sacoleiros, e sua atividade, quando ilícita, é o descaminho. Cardin (2010, p. 23) chama de circuito sacoleiro a esta atividade e a define como: "o conjunto de relações sociais desenvolvidas durante o percurso realizado pelas mercadorias que saem do município paraguaio de Ciudad del Este e entram no Brasil de forma ilegal, via Foz do Iguaçu”. Rabossi (2004) também acrescenta: “o fenômeno da ida dos sacoleiros ao Paraguai começou a tornar público um fluxo que já sucedia fazia tempo pela mão dos grandes contrabandistas: os produtos importados de todo tipo que ingressava no Brasil” (p. 250).

Esta onda de comércio levou a um maior crescimento das cidades fronteiriças e, aliado ao turismo que vinha sendo incentivado na fronteira, completou o quadro que encontramos hoje. Conforme nos informa Eric G Cardin:

\begin{abstract}
no final da década de 1980 o município de Foz do Iguaçu/PR passava por um momento particular. A recessão econômica nacional era agravada no contexto local pelas especificidades promovidas pela aproximação do término da construção da Usina de Itaipu, que já não estava contratando os trabalhadores oriundos de outras localidades que buscavam emprego na barragem e, ao contrário, estava iniciando o processo de diminuição da mão-de-obra utilizada até então. Esta situação promoveu o aumento das atividades informais na região, contribuindo com o desenvolvimento da organização dos camelôs e ambulantes da cidade (CARDIN. 2006).
\end{abstract}

Para controlar os fluxos de bens e capitais, controlar o acesso ao país e fiscalizar o tráfico de drogas e armas, o contrabando e o descaminho, implementou-se em Foz do Iguaçu a mais bem vigiada fronteira do Brasil. No entanto, sabe-se que este esforço tem sido insuficiente para coibir o tráfico de drogas e armas, o contrabando (principalmente de cigarros) e o descaminho (de bens industrializados importados principalmente da China).A política de fronteiras nacional está estabelecida no Plano Estratégico de Fronteiras (PEF), que foi criado em 2010, e:

reúne ações destinadas ao fortalecimento da prevenção, controle, fiscalização e repressão dos delitos transfronteiriços, por meio da atuação integrada dos órgãos de segurança pública, da Secretaria da Receita Federal do Brasil e das Forças Armadas. Dentre os principais delitos transnacionais 
e ambientais, o tráfico de drogas e o crime organizado figuram no centro da agenda de operações (Ministério da Defesa).

A partir daí abre-se muitas siglas que tentam dar conta da complexidade do tema em foco. Temos a Estratégia Nacional de Segurança Pública nas Fronteiras (ENAFRON), um programa no âmbito da Secretaria Nacional de Segurança Pública (SENASP) que coordena esforços de diferentes órgãos federais, estaduais e municipais relacionados à segurança pública nas fronteiras. O programa se propõe a diagnosticar, acompanhar e avaliar; integrar os sistemas e cooperações; uniformizar a política nacional; inovar as tecnologias; lidar com política de pessoal e inteligência de segurança pública. Todos estes pontos visam fomentar estruturas de prevenção e repressão aos ilícitos fronteiriços. (GUIA ENAFRON, v. II, p. 8). Já os GGIFs (Gabinetes de Gestão Integrada de Fronteiras) representam um avanço no PEF e vem a acrescentar ao ENAFRON. Os GGIFs buscam fomentar a interlocução entre o governo federal e os Estados. Instituído pelo Decreto $n^{\circ} 7496$, de 8 de junho de 2011, o Plano Estratégico de Fronteiras prevê a fiscalização, repressão, controle e prevenção de delitos entre fronteiras brasileiras.

No entanto, há modos e modos de ver a prática das ilegalidades:

\footnotetext{
o ilegalismo não é um acidente, uma imperfeição mais ou menos inevitável. É um elemento absolutamente positivo do funcionamento social, cujo papel está previsto na estratégia geral da sociedade. Todo dispositivo legislativo dispôs espaços protegidos e aproveitáveis em que a lei pode ser violada, outros em que pode ser ignorada, outros enfim, em que as infrações são sancionadas. (...) Ao final de contas, diria que a lei não é feita para impedir tal ou tal tipo de comportamento, mas para diferenciar as maneiras de tornear a própria lei (FOUCAULT, 1975).
}

Assim, temos uma estrutura pronta para a fiscalização em nossas fronteiras, no entanto elas ainda são muito porosas e a realidade mostra que o maior sucesso desta estrutura está em combater parte do descaminho, principalmente o praticado por pequenos sacoleiros, sem contatos, sem rotas elaboradas, sem dinheiro de reserva para cobrir as apreensões, sem conhecidos para influenciar nas decisões quando são pegos transportando acima da cota, sem opções viáveis no mercado de trabalho. Estas pessoas se lançam Brasil adentro correndo o risco de assaltos, cruzam a fronteira, gastam em dólar, correm riscos de terem apreendidos seus produtos, voltam para suas cidades e 
tentam revender com algum lucro os bens adquiridos. São malvistos pelos demais trabalhadores, como se fossem uma classe à parte, marginalizada, visto como se roubassem algo, pois o Estado os rotula como sonegadores de impostos, e afirma que prejudicam a indústria nacional.

Nas palavras de Albuquerque (2014, p. 61):

\begin{abstract}
A produção de leis e operações estatais de controles nas fronteiras sempre produzem suas sombras, margens e brechas para variadas formas de gestão diferencial de ilegalismos (TELLES, 2009; RABOSSI, 2008). Controles e passagens, limites e intercâmbios são dois lados de uma mesma moeda fronteiriça em que se realizam muitas negociações da própria fronteira. Os agentes estatais controlam, permitem, toleram, recebem propinas de diferentes agentes sociais nos postos de controle e estes agentes do descaminho e contrabando inventam permanentemente novos trajetos e percursos diante da intensificação e rigidez das leis e operações de controle fronteiriço. A polaridade simplificadora entre a negativa ausência de controle das fronteiras e a positiva solução dada por mais controle e fiscalização não dá conta da complexa e heterogênea realidade fronteiriça, definida permanentemente por seus dinamismos, paradoxos e ambivalências.
\end{abstract}

\title{
COMO SER UM SACOLEIRO
}

Para ser um sacoleiro não há a necessidade de andar com uma sacola tipicamente colorida nos ombros, como se tivesse um outdoor e uma seta apontando para si próprio. O sacoleiro típico é facilmente distinguido do turista, pois suas roupas não são novas ou seguem a última moda no Brasil. São na maioria homens, mas há um contingente grande de casais, além de mulheres em duplas ou em maiores grupos (o que facilita sua defesa em relação a assédio sexual indesejado). A regra é não chamar a atenção e parecer que somos moradores locais, e que fazemos um movimento comum de ida e volta pela fronteira.

O olhar não é o de quem está espantado ou curioso, tem-se que se locomover como se estivéssemos no Brasil. Aliás, devido à convivência de décadas de brasileiros em Ciudad del Este não há a necessidade de se tentar falar em espanhol, o português é normalmente falado e entendido. Por outro lado, não ocorre o mesmo quando os paraguaios falam em espanhol, e principalmente quando falam em guarani, pois falam para não serem entendidos, principalmente quando fazem brincadeiras às custas dos estrangeiros. Tal prática pode ser entendida como sendo mais um exemplo de tática, nos 
moldes expostos por Certeau (1994), utilizada por um grupo em situação de fragilidade para se contrapor a outro, que neste caso usufrui de poder econômico.

Evidentemente, para ser um sacoleiro temos que atravessar a ponte e passar pela fiscalização com algum produto, ou volume, que chame a atenção da fiscalização, e que por tal motivo deva ser camuflada ou escondida de alguma forma no momento da passagem. As táticas serão elencadas mais adiante no texto. Tal aparência tenta emular a de um morador local, que foi ao país vizinho fazer uma compra simples, não o descaminho propriamente dito.

Como pode-se notar, e como citado acima, utilizamos da Observação Participante para conseguirmos as informações constantes deste trabalho. Baseamo-nos nas iniciativas de Malinowski (1978), Geertz (2008), White Foote (2005), Clifford (1998), Da Matta (1978), Velho (1978), entre outros. Tal prática apresenta algumas peculiaridades, a saber, no caso de nossa pesquisa houve mais de um ano de trabalho de campo, no entanto não havia como manter os mesmos pesquisados, apenas os papéis eram fixos, pois os indivíduos variavam diariamente. Nas palavras de Michael Angrosino (2009, p. 17): "Malinowski e Boas eram ambos fortes defensores da pesquisa de campo e ambos defendiam aquilo que veio a ser conhecido como observação participante, um modo de pesquisar que coloca o pesquisador no meio da comunidade que ele está estudando.”

\section{AS REGRAS DO “JOGO”}

Há uma tendência em se usar o termo estratégia para se fazer referência a forma de atuação dos sacoleiros. Em grande medida, o termo aparece preferencialmente nas discussões cotidianas quando se tenta expressar o fato de que alguém, ou um grupo de indivíduos, tem um plano, ou um meio de agir, estruturado visando a obtenção de um fim qualquer. No entanto, há nas Ciências Sociais, uma diferenciação entre os termos estratégia e tática. Esta diferenciação é didática, e é uma ferramenta útil para que saibamos de pronto qual é o tipo de indivíduo, ou grupo, a que nos referimos quando aplicamos um termo ou outro.

Quando usamos estratégia, e não tática, nos referimos a um ou mais indivíduos que tem uma posição tal, no arranjo daquele recorte observado, que poderíamos chamar 
de dominante. Sua forma de agir e de se relacionar no espaço observado reflete sua capacidade em articular os meios necessários para a obtenção dos resultados esperados. Segundo Certeau (1994), tal sujeito, ou sujeitos, tem um lugar próprio, lugar este que expressa seu querer e poder. Sua estratégia é elaborada para agir sobre os outros, sendo um reflexo do seu modo de interagir com estes outros.

Já quando usamos o termo tática, e não estratégia, estamos nos referindo a um indivíduo, ou grupo de indivíduos, que está na posição deste outro citado acima. Este tem que construir uma tática, um modo de agir criado por aquele que não detém um lugar próprio, neste esquema analisado. Dotados de querer, mas desprovidos da posição de poder e de realizar, este outro usa por vezes de astúcia para subverter a ordem estabelecida pelo detentor de um lugar próprio. Assim, a tática se apresenta como a arte do mais fraco no duelo silencioso com o detentor deste lugar próprio (CERTEAU, 1994). Portanto, “as práticas cotidianas (estratégicas e táticas) são lugares e espaços de disputas, confrontos e rupturas que reforçam e subvertem as formas de poder e saber." (CERTEAU, 1994, apud ALBUQUERQUE, 2012, p. 190).

Neste ponto é que podemos caracterizar de melhor forma como cada um dos sujeitos se organizam no espaço entre as duas cidades articuladas por meio de codependências recíprocas e irregulares, onde os comerciantes e o governo, das instâncias controladoras do território no Paraguai, têm como estratégia de obtenção de dólares a venda, por preços subvencionados (já que os habitantes do Paraguai têm de pagar IVA(Imposto sobre Valor Agregado) de 10\% sobre os preços praticados aos brasileiros), de produtos importados. Constata-se que a Receita Federal brasileira e os seus apoios (Polícia Federal, Força Nacional, Polícia Rodoviária Federal, Polícia Militar do Estado do Paraná, Guarda Municipal, Forças Armadas, etc.) tem como estratégia o combate ao descaminho, impedindo a passagem de mercadorias com preços somados superior ao permitido por uma cota de US\$ 300,00 por mês.

Mesmo assim, zonas de fronteiras são um espaço privilegiado onde podemos encontrar as práticas mais variadas para a obtenção de vantagens, conforme afirma Cardin (2015, p. 72): "além de um recurso econômico, a fronteira é um espaço de geração de estratégias e táticas de exercício da cidadania das populações que vivem entre dois Estados nacionais". Neste mesmo sentido, Albuquerque (2015, p. 119) nos informa: 


\begin{abstract}
As fronteiras nacionais estão atravessadas por muitas fronteiras simbólicas. No caso dessa migração e circulação transfronteiriça, as fronteiras entre desenvolvimento e atraso, limpeza e sujeira, original e falsificado, revelam jogos de poder e saber sutis entre nós e eles e possibilitam compreender as estratégias, as táticas e os diversos dispositivos de controle a partir de um olhar micro para as situações e processos sociais nas zonas fronteiriças. Uma forma de ver e praticar a fronteira (
\end{abstract}

Como podemos ver, os sacoleiros, parte desprovida de um lugar próprio, tendo de adotar um conjunto de táticas variadas na busca da obtenção de lucro, com a importação e com o comércio de mercadorias adquiridas e trazidas ao território nacional do Brasil de forma que fere a legislação em vigor. A escala de forças é desigual, e o que equilibra um pouco são os números de sacoleiros em relação aos de funcionários da Receita Federal disponíveis para a fiscalização.

\title{
DA IMPREVISIBILIDADE DO REAL
}

Chegamos, finalmente, ao assunto principal do texto, a saber, quais são as táticas utilizadas pelos sacoleiros para passarem com suas mercadorias, adquiridas no Paraguai, pela aduana de Foz do Iguaçu, localizada na Cabeceira da Ponte da Amizade. Conforme o título da seção anuncia, as táticas que podem ser aplicadas pelos sacoleiros podem variar muito, e respondem às estratégias empregadas pela Receita Federal e seus apoios.

\footnotetext{
Segundo a legislação brasileira, a Receita Federal do Brasil (RFB) tem a precedência sobre os demais órgãos no controle aduaneiro, ou seja, cabe prioritariamente à RFB e aos seus servidores controlar a entrada, a permanência, a movimentação e a saída de pessoas, veículos e mercadorias de portos, aeroportos, pontos de fronteira e recintos alfandegados, ou embarque e desembarque de viajantes, procedentes do exterior (GODOI e CASTRO, 2011, p. 17-18).
}

Pode-se passar pela ponte de algumas formas padrão: a pé; de moto; de ônibus regular; de ônibus de viajem; de ônibus de excursão; de carro particular com placas de outras cidades e estados; de carro particular com placas locais; de vans paraguaias; vans brasileiras de turismo; de taxi. Há ainda vans de estudantes e ônibus de estudantes, que são identificadas, mas estas raramente, ao que sabemos, são associadas ao descaminho. Houve uma forma que não dependia da ponte, mas sim do rio, que era a utilização de 
pequenas embarcações, que cruzavam o Rio Paraná, nas proximidades da Ponte da Amizade, lotadas de caixas embaladas em plásticos escuros. Tal prática estava ficando mais rara devido às operações policiais de patrulha desta parte do rio, e cessaram de vez, nesta parte do rio, devido à instalação de um posto permanente da Polícia Federal, contando com barcos velozes portando armamento pesado.

A travessia a pé é a mais tradicional e econômica, sendo que as imagens mais icônicas da atividade sacoleira se associam ao lançamento de fardos de cigarro e mercadorias variadas por cima da cerca que flanqueava a ponte em décadas passadas. Tal prática está extinta devido ao policiamento no lado brasileiro e às reformas que aumentaram as grades e a cerca próxima da cabeceira. Os caminhos feitos no mato, abaixo da ponte, também desapareceram da paisagem, e estão no passado. Passar a pé depende de sorte, pois os agentes da Receita Federal fiscalizam de acordo com seu próprio critério. Assim, há momentos em que não há ninguém no posto que fiscaliza os transeuntes, outros em que se pode encontrar de um a cinco fiscais, contando ou não com apoio da Polícia Federal ou outra força policial, ou até do exército. Tudo é incerto e complexo.

A tática é disfarçar os produtos: no inverno passa-se dentro de cobertores, vendidos nos mesiteros do Paraguai (cf. RABOSSI, 2004). Se for muita coisa faz-se mais de uma viagem, e opta-se por mudar de forma de levar em cada uma das vezes; se der para passar de uma vez anda-se atrás de um (ou mais) pedestres com muitas bolsas, pois a probabilidade de eles serem parados e de não sobrar fiscal para deter o sacoleiro é maior; espera-se que um ônibus regular passe na aduana, pois os mesmos fiscais fazem as duas funções; geralmente se conta com a conjunção de dois ou mais destas táticas para se ter sucesso na passagem a pé pela ponte.

A travessia de moto é a mais rápida, já que os quinhentos metros de ponte são passados em minutos, evitando-se o trânsito ruim do trecho, mas a exposição do que se comprou no país vizinho é tão grande quanto à dos pedestres. Alguns motoqueiros, todos paraguaios (os mototaxistas brasileiros levam ao Paraguai e os paraguaios fazem o trajeto oposto), escondem pequenos volumes em partes ocas da moto ou em capacetes. A tática tem a vantagem do número, pois há muitas motos passando e é impossível fiscalizar todas. 
A tática de utilizar-se de ônibus regular, que liga a Rodoviária Internacional de Foz do Iguaçu à rodoviária de Ciudad del Este, é uma das preferidas, pois, como já dissemos acima, o fiscal do ônibus é o mesmo dos pedestres, e tal atribuição dupla traz uma chance maior de que haja pouca fiscalização, ou que o ônibus seja liberado sem sequer parar. O sacoleiro pode colocar suas sacolas abaixo dos bancos, das pernas, nas costas, dividir entre outros passageiros (o que é raro, por medo de ter drogas ilegais nos pacotes). Há, nesse sentido, uma imagem muito forte da fronteira entre Brasil e Paraguai:

(...) podemos perceber a maneira como são construídas e reforçadas as imagens do Paraguai como o lugar perigoso do crime organizado, do tráfico de armas, drogas e especialmente como país da falsificação, imagem tão cotidiana e tão divulgada em todo o Brasil em que falsificação já se tornou sinônimo de Paraguai (RABOSSI, 2010, apud ALBUQUERQUE, 2014, p. $58)$.

O clima de tensão é perceptível, mesmo nos passageiros sem mercadorias, pois a presença de um funcionário do governo olhando e vasculhando é muito incômoda para todos. Abrir mochilas, bolsas, ter de se levantar dos bancos, ter de descer para ter seu CPF cadastrado no sistema da receita (o motorista dá a estes passageiros um passe para tomar, sem custos extras, outro ônibus após a liberação pela Receita Federal), tudo neste ponto carrega o ar com um clima de tensão, que só se dissipa após o ônibus começar a se mover em direção à rodovia.

Em 2004 Fernando Rabossi registrava vividamente a experiência de ser parado na aduana, estando num ônibus regular, por um fiscal, acompanhe:

Um Policial Federal fez sinais ao motorista para deter o ônibus. O homem de bigodes que estava parado no meu lado me perguntou em voz baixa e com angústia, "Tenho cigarros pra trocar, tem alguma coisa?" Uma mulher jovem, sentada atrás de mim, se ofereceu a pegar uma sacola com 5 pacotes-, eu peguei outra. A moça que estava no meu lado me pediu para passar dois teclados de computador. Os que tinham bastante mercadoria desceram. O homem de bigodes que estava no meu lado, antes de descer, escondeu uma sacola com cigarros embaixo de um assento. Um homem com colete e quepe com as iniciais da Receita Federal subiu no ônibus e começou caminhar olhando para cada um dos que tinham ficado acima. "Que tem aí?", perguntou a um homem com um bolsão. "Só isso", lhe respondeu abrindo e deixando ver alguns brinquedos. Continuou andando. "Isso aqui de quem é?" perguntou apontando para umas caixas. "Meu", outro respondeu, "são dois ventiladores", esclareceu. O fiscal rasgou as caixas para ver que havia dentro 


\begin{abstract}
e continuou. "E você?" me perguntou. "Só isso", respondi mostrando-lhe os dois teclados e os cigarros. Eu estava também com meu bolso que ele abriu e revisou apalpando com suas mãos entre a roupa. $\mathrm{O}$ deixou aberto e continuou. "Essas sacolas de quem são?" Ninguém respondeu. O fiscal tirou quatro sacolas de embaixo do assento, cada uma com 5 pacotes de cigarros. Pegou a primeira e tentou jogá-la pela janela, mas o cálculo foi errado: a sacola bateu na borda da janela e caiu em cima de uma mulher. Ninguém falava. Ela também não abriu a boca. $O$ fiscal pegou novamente a sacola e jogou-a com melhor pontaria. As outras sacolas seguiram o mesmo caminho. Olhando para a caixa de um monitor, falou para o homem que estava no seu lado, "Isso aí... vai declarar." O homem desceu. Outro, com uma enorme sacola de produtos de computação, teve o mesmo destino. Ao fundo do ônibus, detrás da roleta, o fiscal abriu umas caixas e começou jogar pacotes de cigarro e mais cigarros pela janela. Cheguei a contar mais de 40 pacotes. $\mathrm{O}$ rapaz que os levava tinha seus olhos com lágrimas. Quando o fiscal se aproximou de onde ele estava, tinha ficado em pé para pedir-lhe por favor que não jogasse sua mercadoria. Mais tarde alguém me explicaria que o rapaz não deveria ter feito isso, "Tem que ficar calado... pra que falou? Uma vez que você está aqui não dá pra pedir 'por favor' (RABOSSI, p. 263).
\end{abstract}

Quando os sacoleiros se utilizam dos ônibus de viajem, linhas que cruzam a Ponte da Amizade com destino a outras cidades do Paraguai, principalmente a capital Asunción, eles tentam disfarçar suas compras no meio das bagagens dos turistas, tentando se passar como tal. Esta tática não é muito utilizada, pois a revista é a mesma dos demais ônibus e a prática já é bem conhecida pela Receita e pelas polícias de apoio.

Já em termos de táticas mais populares, passar com mercadorias pela ponte utilizando um ônibus de excursão é uma das piores opções, já que os fiscais param os ônibus e fazem os passageiros descerem todas as bolsas, caixas, pacotes e malas, para daí fiscalizar mais detalhadamente. Ao mesmo tempo os sacoleiros pedestres têm neste momento a melhor chance de passar sem serem parados, pois a vistoria é bem demorada, dando muitas chances de escapar à fiscalização.

Muitos sacoleiros tentam dar a impressão de que são turistas e tentam atravessar a aduana utilizando algum carro particular com placas de outras cidades e estados. As chances de passar são boas, mas dependendo do estado de emplacamento o carro tem mais chances de ser parado, não tanto pela suspeita de haver descaminho, mas pela possibilidade de haver drogas no veículo. Muitos veículos destes têm locais secretos, fundos falsos, aberturas nos forros, onde pode-se esconder mercadorias, e/ou drogas.

De todas as formas de se passar pela ponte, e pela fiscalização de forma a não ser revistado, a melhor é tentar passar com carro particular com placas locais, as chamadas placas "A". Nunca fomos parados passando com carro com placa local, nem 
vimos algum carro emplacado no município de Foz do Iguaçu sendo parado pelos fiscais na aduana. No entanto, conseguir um carro com placas de Foz do Iguaçu apenas para passar mercadoria pode vir a ser um investimento muito alto para a maioria dos sacoleiros. Além disso, as placas estão mudando para o novo modelo "MERCOSUL" (Mercado Comum do Sul) o que mudará a forma de obter vantagens deste expediente.

Durante o período em que realizamos a pesquisa, aproximadamente três anos, o meio de transporte mais utilizado pelos sacoleiros, de longe, foram as vans paraguaias. Elas são facilmente detectáveis na paisagem, pois são modelos que não são encontrados no Brasil, muitas com as portas do lado contrário, como se fossem fabricadas para Hong Kong, ou outro país que utilize a "mão inglesa". As vans estão para o trânsito de Ciudad del Este como as "kombis" estão para o trânsito da cidade do Rio de Janeiro. Os fiscais têm grande interesse em pará-las, já que sabem que há muito espaço para guardar mercadorias embaixo dos bancos e atrás, no bagageiro.

Há uma organização entre os motoristas das vans, com fila de chegada, pessoas chamando passageiros, policiais fiscalizando do lado paraguaio, tudo para fazer com que o trânsito ande e que nenhum ganhe mais que os outros. Quando um paraguaio consegue convencer a um passageiro entrar numa van fora do ponto de embarque ele recebe do motorista da van por volta de dois mil guaranis, algo em torno de $\mathrm{R} \$ 1,30$.

Durante a pesquisa fomos cadastrados no sistema duas vezes, a primeira vez não há incidência de tarifa, que seria de $50 \%$ sobre o valor das mercadorias em posse do sacoleiro, nem multa, que seria de $25 \%$ sobre o mesmo valor. O total de $75 \%$ inviabiliza totalmente a atividade dos sacoleiros e abre um rombo em suas contas. Há uma tolerância de um cadastramento a cada trinta dias, caso contrário as penalidades são aplicadas.

Quando há a apreensão, devido ao volume elevado dos mesmos itens, o prejuízo é total, e podemos ver os desolados sacoleiros, e alguns turistas desavisados, sentados do lado de fora do prédio da aduana, esperando a confecção do boleto bancário, a ser pago no Banco do Brasil (há um posto no local), para poderem retirar seus onerosos bens.

Outra forma de tentar se evadir da fiscalização é passar pela receita utilizando vans brasileiras de turismo. Estas são fisicamente diferentes das vans do Paraguai, tem uma padronização regular, com logo e placas especiais. São pouco paradas pela 
fiscalização, mas devido à possibilidade de penalidades, cabíveis aos motoristas destas vans, não há muita utilização por parte de sacoleiros.

Outra forma de se passar por turista é tomar um dos táxis do Paraguai. Eles são padronizados e fazem, como as motos, apenas o trajeto Ciudad del Este - Foz do Iguaçu, cabendo aos táxis brasileiros o trajeto oposto. Este expediente é bastante utilizado por sacoleiros, e do mesmo modo bastante fiscalizado pela Receita Federal, perdendo apenas para as vans paraguaias na quantidade de paradas no posto de fiscalização.

Mas como informa o título desta seção do texto, a realidade é imprevisível, assim cada uma destas táticas acima está sujeita a muitas variações, que se articulam na obtenção do resultado final dependendo da estratégia aplicada pela Receita Federal e seus agentes. Assim, houve uma variação enorme na fiscalização entre os governos Dilma Rousseff e Michel Temer, como também a cada mudança de chefia, a cada nova operação, como Muralha ou Ágata, e mudanças simplesmente de turno de agentes ou rodízio destes agentes. Já fomos hostilizados por uns, tolerados por outros, revistados, como também tiramos fotos de agentes (a pedido deles), passamos por mais de dez soldados fazendo revistas rigorosas em todos os pedestres apenas dando bom dia ao nos aproximarmos. Não há padrão (além das táticas aplicadas, conforme vimos acima), nem há um dia igual ao outro na fronteira.

\section{CONCLUSÃO}

Como pudemos observar acima, fizemos um apanhado das táticas utilizadas por sacoleiros, importadores informais e ilegais (por não respeitarem as cotas legais de importação) para a passagem pela fiscalização na aduana brasileira, tentando evitar o pagamento de impostos e a apreensão de produtos, constituindo a prática do descaminho. Tais táticas variam bastante na forma e durante os tipos de abordagem praticadas pela Receita Federal em cada momento. Para respondermos ao intuito da pesquisa a que nos propusemos aplicamos a observação participante, nos fazendo passar por sacoleiros e utilizando dos mesmos expedientes destes, ou observando durante o processo os demais modos de tentativa de obtenção de êxito em suas práticas. Cremos que os resultados foram obtidos, já que conseguimos adquirir conhecimento de muitos 
tipos de táticas utilizadas pelos agentes do descaminho em sua busca por lucro em sua atividade.

Ao utilizarmos do expediente de nos passarmos por sacoleiros pudemos sentir na pele todos os conflitos de um personagem tão típico desta fronteira do Brasil. Fugir a uma fiscalização, tentar burlar um agente do Estado, gera um nível de tensão muito alto, pois há o combate invisível entre a estratégia do Estado contra as táticas de um grupo de homens e mulheres, desempregados e sem esperança, para manterem uma renda que possa lhes dar um conforto que um salário não os daria, devido às suas carências, geralmente de cunho educacionais e técnicas.

Este estudo ainda carece de muita complementação, principalmente da visão do outro lado, do lado dos agentes da lei, do Estado. Ao mesmo tempo é muito mais fácil se inserir num grupo tão heterogêneo como o dos sacoleiros, do que se inserir num grupo como o dos fiscais da Receita Federal, e a abordagem do problema mudaria completamente. Olhar por dentro o problema nos dá detalhes, mas perdemos a paisagem inteira neste processo. Mas o pesquisador é mesmo míope, e é por isto que ele se esforça tanto para olhar os fatos à sua volta.

\begin{abstract}
A partir daí, segue-se uma peculiaridade no caminho: como simples tema de fato empírico, nosso conhecimento da cultura... culturas... uma cultura... cresce aos arrancos. Em vez de seguir uma curva ascendente de achados cumulativos, a análise cultural separa-se numa sequência desconexa e, no entanto, coerente de incursões cada vez mais audaciosas. Os estudos constroem-se sobre outros estudos, não no sentido de que retomam onde outros deixaram, mas no sentido de que, melhor informados e melhor conceitualizados, eles mergulham mais profundamente nas mesmas coisas. Cada análise cultural séria começa com um desvio inicial e termina onde consegue chegar antes de exaurir seu impulso intelectual: Fatos anteriormente descobertos são mobilizados, conceitos anteriormente desenvolvidos são usados, hipóteses formuladas anteriormente são testadas, entretanto o movimento não parte de teoremas já comprovados para outros recém- provados, ele parte de tateio desajeitado pela compreensão mais elementar para uma alegação comprovada de que alguém a alcançou e a superou. Um estudo é um avanço quando é mais incisivo - o que quer que isto signifique - do que aqueles que o precederam; mas ele se conserva menos nos ombros do que corre lado a lado, desafiado e desafiando (GEERTZ, 2008, p. 18).
\end{abstract}

Embora a prática do descaminho feita por sacoleiros não é mais como era no passado recente, quando milhares de pessoas chegavam e saíam pelas estradas do Paraná levando parte de suas expectativas em sacolas coloridas, cremos que ainda há 
muito ouro a ser garimpado nestas margens de rio. Nos referimos ao fato de o modo do Estado se posicionar em relação aos mais fracos elos de uma cadeia produtiva enferrujada mostra a face real de suas preocupações. Esta face nos interessa pesquisar e divulgar, e nossa pretensão é avançar no estudo do Estado e suas práticas.

\section{BIBLIOGRAFIAS}

ALBUQUERQUE, J. L. C. A produção das fronteiras nacionais no telejornalismo brasileiro: análise de algumas séries especiais de reportagem sobre as fronteiras do Brasil. Segurança, Justiça e Cidadania: Pesquisas Aplicadas em Segurança Pública. V. 4, p. $53-70,2014$.

ALBUQUERQUE, J. L. C. Limites e paradoxos da cidadania no território fronteiriço. Geopolitica(s). Revista de Estudios sobre Espacio y Poder, V. 3, p. 185 $205,2012$.

Migração, circulação e cidadania em território fronteiriço: os brasiguaios na fronteira entre o Paraguai e o Brasil. Revista Tom,. V. 1, p. 97-122, 2015.

ANGROSINO, M. Etnografia e observação participante. Porto Alegra: Ed. Artmed. 2009.

BEZERRA, A. K. G. A Pesquisa etnográfica e as especificidades da observação participante. Vinheta, PB, 2010.

CARDIN. E. G. A Expansão do capital e as dinâmicas da fronteira. Tese (Doutorado em Sociologia). Araraquara: UNESP, 2010.

Estado, trabalho e capitalismo nas fronteiras. Revista katálysis, Florianópolis,

V. 21, N. 2, p. $305-312$, maio 2018. Disponível em <http://www.scielo.br/scielo.php?script=sci_arttext\&pid=S1414-

49802018000200305\&lng=

pt\&nrm=iso>. Acesso em: 01 jun. 2019.

Sacoleiros e laranjas na tríplice fronteira: uma análise da precarização do trabalho no capitalismo contemporâneo. Dissertação (Mestrado em Sociologia). Araraquara: UNESP, 2006.

CARDIN, E. G.; CAMAL-CHELUJA, T. L.; ARRIAGA-RODRIGUEZ, J. C. Fronteiras e dinâmicas fronteiriças en América Latina. Chetumal/México: UNQroo, 2015.

CERTEAU, M. A Invenção do cotidiano: artes do fazer. Petrópolis, RJ: Vozes, 1994. 
CLIFFORD, J. A experiência etnográfica - antropologia e literatura no século XX. (Org.) José Reginaldo Santos Gonçalves. Rio de Janeiro: Editora UFRJ. 1998.

DA MATTA, R. O Ofício de Etnólogo, ou como ter "Anthropological Blues". In: NUNES E. O. (Org.). A aventura sociológica. Rio de Janeiro: Zahar, 1978.

FOUCAULT, M. Vigilar y castigar: nacimiento de la prisión. Buenos Aires: Siglo Veintiuno Editores, 1989.

GEERTZ, C. A interpretação das culturas. Rio de Janeiro: LTC, 2008.

Nova luz sobre a antropologia. Rio de Janeiro: Zahar, 2001.

GODOI, R.; CASTRO, S. Fronteiras abertas: um retrato do abandono da aduana brasileira. Sindireceita/Gráfica Stephanie, 2011.

LIMA, F. R. F. Desenvolvimento regional na fronteira Foz do Iguaçu/BR - Ciudad del Este/PY. Tese (Doutorado em Geografia). Curitiba: UFPR, 2011.

RABOSSI, F. Nas ruas de Ciudad del Este: vidas e vendas num mercado de fronteira. Tese (Doutorado em Antropologia Social). Rio de Janeiro: Museu Nacional, 2004.

VELHO, G. Observando o Familiar. In: NUNES, E. O. (Org.). A aventura sociológica. Rio de Janeiro: Zahar, 1978.

WHYTE, W. F. Sociedade de esquina: a estrutura social de uma área urbana pobre e degradada. Tradução de Maria Lucia de Oliveira. Rio de Janeiro, Jorge Zahar, 2005. 